\title{
Exergames Experience in Physical Education: A Review
}

Authors' contribution:

A) conception and design of the study

B) acquisition of data

C) analysis and interpretation of data

D) manuscript preparation

E) obtaining funding

\author{
Cesar Augusto Otero Vaghetti ${ }^{1 \mathrm{~A}-\mathrm{E}}$, Renato Sobral \\ Monteiro-Junior ${ }^{2 \mathrm{~A}-\mathrm{E}}$, Mateus David Finco ${ }^{1 \mathrm{~A}-\mathrm{E}}$, Eliseo \\ Reategui $^{3 \mathrm{~A}-\mathrm{E}}$, Silvia Silva da Costa Botelho ${ }^{4 \mathrm{~A}-\mathrm{E}}$ \\ ${ }^{1}$ Federal University of Pelotas, Brazil \\ ${ }^{2}$ State University of Montes Carlos, Brazil \\ ${ }^{3}$ Federal University of Rio Grande do Sul, Brazil \\ ${ }^{4}$ Federal University of Rio Grande, USA
}

Exergames are consoles that require a higher physical effort to play when compared to traditional video games. Active video games, active gaming, interactive games, movement-controlled video games, exertion games, and exergaming are terms used to define the kinds of video games in which the exertion interface enables a new experience. Exergames have added a component of physical activity to the otherwise motionless video game environment and have the potential to contribute to physical education classes by supplementing the current activity options and increasing student enjoyment. The use of exergames in schools has already shown positive results in the past through their potential to fight obesity. As for the pedagogical aspects of exergames, they have attracted educators' attention due to the large number of games and activities that can be incorporated into the curriculum. In this way, the school must consider the development of a new physical education curriculum in which the key to promoting healthy physical activity in children and youth is enjoyment, using video games as a tool. In this context, the aim is to conduct a brief review of the use of exergames in physical education curriculum, exploring school curriculum, digital culture, and motivation and enjoyment for the learning processes in the video game environment

curriculum, active gaming, exergaming, experience

\section{Introduction}

Video games (VGs) first became available to the public in the late 1970s, offering a new possibility for human-computer interaction (Boyle, Connolly, \& Hainey 2011). Initially, VGs were accessible mainly in arcades, which housed VGs and pinball machines that mixed dexterity and luck. These places still exist today. Years later, names like Atari, Odyssey, and Intellivision arose and established the culture of VGs as a leisure practice. Statistics show that the total number of consumer spending in the VG industry in 2013 in the USA produced \$21.53 billion (ESA 2014), and 97\% of US teens play some type of computer game (Kowert, Domahidi, Festl, \& Quandt 2014). In this context, sedentary lifestyle is likely to increase among children and youngsters, and this is partially due to sedentary leisure time (Gilmore, Duhé, Frost, \& Redman 2014).

One of the underlying causes for the reduction in physical activity is the advancement of technology. Today, children spend a lot of time watching television, using cell phones, and playing VGs, more time than anything else besides sleeping (Rosenberg 2013). The amount of VG and media screen time is related to body 
mass variables and inactivity. It is important to examine their potential health effects. According to Ballard et al. (2009), the highest rates of media use are related to a greater likelihood of being overweight or obese. TV viewing and computer using were the main items stated for sedentary behavior in a research involving 902 adolescents (Sigmundová, El Ansari, Sigmund, \& Fromel 2011). This is a reality, and in this context the best solution is to try to associate the use of technology with increased levels of physical activity.

In 2006, Nintendo ${ }^{\circledR}$ developed Wii Sports, which allows users to experience the actual movements of various sports, including golf, boxing, tennis, bowling, baseball, yoga, skateboarding, and snowboarding. The new generation of VGs could expand the range of opportunities for physical activity available to adolescents (Graves, Stratton, Ridgers, \& Cable 2007). These types of VGs are known in the literature as exergames (EXGs) due to the use of sensing technologies enabling the combination of VGs and physical exercise (Suhonen, Väätäjä, Virtanen, \& Raisamo 2008; Sinclair, Hingston, \& Masek 2007). In addition, EXGs are now considered to be a new educational tool, especially in the health sciences (Papastergiou 2009; Staiano \& Calvert 2011). Because human movement is a key feature in these types of VGs, they can be used as a learning/therapeutic tool in areas such as physical education (PE), medicine, and physiotherapy. Some authors (Sothern 2004) have highlighted different aspects of educational VGs and have classified traditional VGs as sedentary activities compared to EXGs. The playful aspects of EXGs and public fascination with virtual reality have contributed to the growing success of such VGs (Suhonen, Väätäjä, Virtanen, \& Raisamo 2008). Using human movement as part of the VG creates a favorable environment for the teaching and learning processes. It establishes EXGs as potential pedagogical tools to be used in educational institutions, rehabilitation clinics, and psycho-pedagogical interventions. They can motivate and create a more attractive learning environment, and they may also increase physical activity levels.

Conceptually speaking, EXGs are consoles that require a higher physical effort to play when compared to traditional VGs. Active VGs, active gaming, exergaming, interactive games, movement-controlled VGs, or exertion games are terms used to define this kind of VG, in which the exertion interface enables a new experience (Mueller, Gibbs, \& Frank 2010). In the field of Human Computer Interaction, many EXGs are being developed with different goals; however, most are not available for domestic use. These games have different purposes, such as obesity treatment (Berkovsky, Bhandari, Kimani, Colineau, \& Paris 2009; Easterly \& Blachnitzky 2009), promoting social interaction (Johnston \& Whitehead 2011), and physical rehabilitation (Benveniste, Jouvelot, Pin, \& Pequignot 2012). These prototypes use different devices to increase physical activity, to measure physical effort, and to improve the experience in the game. Some of these devices include heart rate monitors (Stach, Graham, Yim, \& Rhodes 2009), treadmill ergometry (Ahn et al. 2009), mixed reality (Khoo, Merrit, \& Cheok 2009), GPS devices (Laikari 2009), and sports equipment (Pijnappel \& Mueller 2013).

The most popular EXG consoles available on the market are Nintendo ${ }^{\circledR}$ (Wii/Wii U), XaviXPORT®, Cybex TRAZER ${ }^{\circledR}$, Sony PlayStation ${ }^{\circledR}$ Move, Konami ${ }^{\circledR}$ Dance Dance Revolution (DDR), iDance ${ }^{\circledR}$, GamerCize ${ }^{\circledR}$, and the Kinect sensor for XBOX ${ }^{\circledR}(360 / O n e)$. The physical interaction enabled by each of these devices may differ a great deal. Nintendo ${ }^{\circledR}$ Wii/Wii U and XaviXPORT ${ }^{\circledR}$ use accelerometers within the controller (i.e., the Wii remote) to measure the user's arm/hand movements in three dimensions; the Sony PlayStation ${ }^{\circledR}$ Move uses a camera system (Eye Toy) to acquire cinematic information from the joystick; Konami ${ }^{\circledR}$ DDR and iDance ${ }^{\circledR}$ both require players to step on a dance mat in a specified pattern of arrows to keep to the rhythm of a chosen song; and the Kinect $\mathrm{Xbox}{ }^{\circledR}$ uses a camera system to acquire cinematic information from the player to rebuild the avatar movements in the VG. Other systems are available, such as the Cybex TRAZER ${ }^{\circledR}$, which uses position tracking devices to provide feedback on a player's position, speed, and heart rate. The XaviXPORT ${ }^{\circledR}$ system has controls similar to Nintendo ${ }^{\circledR}$ Wii. Lastly, the Gamercize ${ }^{\circledR}$ steppers allow players to play any game compatible with the Xbox ${ }^{\circledR}$ or PlayStation ${ }^{\circledR}$ as long as the player is stepping at a consistent cadence.

Exergaming has the potential to contribute to PE programs by supplementing the current activity options and increasing student enjoyment. These types of games can provide engaging activities for schools. One example of this approach is West Virginia's statewide EXG curriculum. In the USA, EXGs like DDR are being 
incorporated not only into PE classes, but also into recesses, lunchtimes, and after-school programs (Staiano \& Calvert 2011).

The aim is to conduct a brief review of the use of exergames in PE curriculum, exploring the school curriculum, digital culture, motivation, and enjoyment for the learning processes in the use of VG environments.

\section{School curriculum and digital culture}

Our current society, in which children bring an entire digital culture to school, is completely different from that of the last century. According to Turkle (1995), the culture of simulation arises in the face of computer models as their representatives and digital games as elements that make such representations. These representations establish a non-linear logic that is part of the screenager generation universe. Rushkoff (1996) used this term when referring to the generation born in the 1980s and beyond, who sit in front of a screen and seek to interact with the latest VGs that require fast movements and demand a sensorimotor intelligence. Immersed in digital social networks, the screenagers are living in cyberspace and developing a social life there, sharing information and performing physical exercise with the use of EXGs. Young people of the twenty-first century participate actively in the construction of the so-called collective intelligence (Lévy 1997), whereas the school does not recognize the ubiquitous nature or various technological forms of education.

The strength of technology is also a characterization of postmodernity because everything is connected and networked. The postmodern society is conditioned by cyberspace. In contrast, the teacher-centered approach based on repetition and memorization still prevails in schools and characterizes modernity. Bringing digital games to the school setting does not mean merely thinking of such a cultural artifact for the purposes of developing math concepts, learning languages, or improving cognitive processes. The school was born in the times of late modernity, with a moralizing proposal to control students. The proposal was grounded in the idea that many pedagogical advances are possible, but some of these advances do not seem to occur in practice. For example, the discovery by educators that joy is central to the process of teaching and learning is echoed in several theories. However, does this finding resonate in the everyday life of schools?

Psychogenetic theories have introduced motivation as an important element for the teaching and learning process. The motivation of VGs could be combined with curricular contents, which Prensky (2003) calls Digital Game-Based Learning. However, young people's intrinsic motivation towards VGs contrasts with their often-noted lack of interest in PE curricular contents. The challenges for the pedagogical practice in PE in the twenty-first century come not only due to the lack of motivation for physical activity and body practices, but mainly because of the possibility of using cyberspace and games as a curricular subject (Vaghetti et al. 2012). Indeed, according to Mellecker and McManus (2008), the key to promoting sustainable activities in childhood is enjoyment; children initiate and sustain technology play because it is fun, exciting, and challenging.

VGs are incredibly complex computer programs that lead the brain to new combinations of cognitive tasks and demand new levels of processing power (Beck \& Wade 2004). This finding confirms the idea that younger generations have different ways of thinking and understanding the world, discovering trails, inventing new ways of experiencing life, and creating different identities as if they were in a continuous metamorphosis. In such a new world order, education for global citizenship is essential in preparing our children and young adults to be agents of change rather than just passive observers of world events, and at the same time living together in an increasingly diverse and complex society and reflecting on and interpreting fast-changing information.

\section{Video game experience: Motivation and enjoyment for learning processes}

What is a game? What happens in the act of playing? Moreover, why are games considered to be fun? Why do they lead players to a kind of hypnosis, a euphoria that seeks the realization of an uncontrollable desire in which time seems to freeze and the pursuit of joy prevails? These questions, posed by Huizinga (1949), allow us to understand the human fascination with games. Games are present in our life when we are born. Rules and fantasies are essential for children to understand the world and its limits. Playing with toys is the main phenomenon and transitional object of childhood from four months of age. At this phase, children already 
play to construct rules, to experience fantasy while maintaining links with reality. Therefore, games may be considered as a sort of bridge between fantasy and reality (Singer \& Singer 2009).

A game is an activity that has clear goals, a start and an end, rules and feedback. A game also offers the possibility to play against an opponent. In addition, games may be seen as a representation of an interactive story. The essence of VGs is the same as that of other games such as chess, poker, golf, puzzles, crosswords, shuttlecock, marbles, table tennis, spinning tops, and sports. Certain elements of VGs, including the recreational aspect, game play, narrative, interface, and immersion, contribute to the fantasy and simulation of games in the digital age despite being defined by game rules and mechanics.

Human experiences in virtual environments and VGs are made of similar elements as real-life experiences. According to Ermi and Mäyrä (2005), the gameplay experience can be defined as an ensemble of the player's sensations, thoughts, feelings, actions, and meaning-making in a gameplay setting. Thus, it is not a property of or a direct cause of certain elements of a VG but something that emerges in a unique interaction process between the VG and the player. According to these authors, immersion is the most important component of the gameplay experience, divided into sensory immersion, challenge-based immersion, and imaginative immersion.

In the game design field, the classic architecture of a VG comprises three different layers: game core, game engine, and game interface. Zea et al. (2009) define the game core as the most important element of the VG as it includes the game's main features such as genre, rules, challenges, and goals. It defines the "personality" or "identity" of the VGs, that is, how to play, how to win, and how to feel. The game core has three main elements: mechanics (computational features), story/narrative (theme of the game, sports, adventure, puzzle), and interactivity (the freedom of the user to change the game). The user experience, according to Sweetser and Wyeth (2005), is focused on three aspects of usability: interface (controls and display), mechanics (interacting with the VG), and gameplay (problems and challenges). However, player enjoyment is the most important goal for computer games. These researchers have developed a model for evaluating player enjoyment in VGs: the gameflow. It consists of eight elements: concentration, challenge, skills, control, clear goals, feedback, immersion, and social interaction.

Finally, the most interesting definition of a game and its elements is defended by McGonigal (2009), who argues that just four features define a game: goals, rules, feedback system, and voluntary participation, in which the variety and intensity of feedback is the most important difference between digital and non-digital games. In computers and VGs, the interactive loop is satisfyingly tight. Gamers can literally see in the animations and count on the scoreboard their actual impact on the VG. The gameplay only gets harder when the player is playing well, creating a perfect balance between difficulty and achievability.

In VG literature, the flow theory is one of the most cited theories about intrinsic motivation as an important element for the learning process. Developed by Mihaly Csikszentmihalyi in 1975, the flow theory has been widely used for VG designers, in which the goal is to engage the player in the game (Chou \& Ting 2003; Voiskounsky, Mitina, \& Avetisova 2004; Sweetser \& Wyeth 2005; Boyle, Connolly, \& Hainey 2011). According to this theory, during the flow experience, the person loses all sense of time and concerns, and the performance and pleasure sensations in the activity are maximized (Csikszentmihalyi 1990). Some authors suggest that the flow theory is an indicator of students' satisfaction concerning cyberspace learning (Shin 2006; Liao 2006). The theory is also called the optimal experience and is closely associated with an autotelic activity. In other words, according to Davis et al. (1992), it refers to the performance of an activity without receiving any reward. It is simply about pleasure. Jackson et al. (2010) state that the flow theory has nine dimensions: challenge-skill balance, action-awareness merging, clear goals, unambiguous feedback, total concentration on the task at hand, sense of control, loss of self-consciousness, transformation of time, and autotelic experience.

The dimensions of the flow theory are important features to the teaching and learning process. Motivation and learning engagement may have a reciprocal relationship (Singh, Granville, \& Dika 2002). Engagement is the level of concentration, involvement, and enjoyment that students may have when they engage in an academic task. Shernoff et al. (2003) found positive relationships between flow and improved learning in adolescents and high school students. To be in this state of engagement, or flow, students need to 
perceive a balance between the challenge of a task and their capability to perform the task successfully. Many studies have shown that individuals who are highly motivated tend to experience high levels of flow (Jackson 1992; Elias, Mustafa, Roslan, \& Noah 2010).

\section{Exergames in physical education curriculum}

EXGs have added a physical activity component to the otherwise seated VG environment, offering an attractive alternative for increasing physical activity and combating some of the health risks of excessive sitting (Lam, Sit, \& McManus 2011). However, according to Sun (2012), very few studies have demonstrated the actual efficacy of incorporating EXGs in PE classes. Kiili et al. (2012) also affirm that little research has been done to study exergaming as a part of classroom activities. If exergaming were to be conceptualized within a pedagogical PE environment, what learning frameworks would be most likely to guide the development of the exergaming curriculum?

According to Ennis (2013), three different categories of PE programs are used by teachers in schools: recreational approaches, public health, and education. Although the impact of EXGs in the recreational and health areas has recently been studied, the incorporation of EXGs in the curriculum is still a field lacking investigation. Fogel et al. (2010) carried out a study with four fifth-grade students in PE classes from a public elementary school. The participants were chosen because they were physically inactive in the PE classroom. The study was conducted during the regularly scheduled PE classes. The researchers found that EXGs produced more physical activity across all four participants than they did in regular PE activities. Further, exergaming was socially acceptable to the PE teacher and students in this study. Lwin and Malik (2014) examined the effectiveness of incorporating exergaming in PE lessons as a platform for imparting health education messages and influencing children's beliefs about and attitudes toward physical activity among fifthgrade school children in Singapore. Results indicated that when children were exposed to framed messages while playing Wii EXGs during education classes, they reported more positive attitudes toward physical activity, self-efficacy, and perceived behavioral control than those who underwent regular PE lessons and were exposed to the same messages. Finco et al. (2015) followed a qualitative observation approach, involving twenty-four students of both genders for three months. Results from this study demonstrated that students who were normally unmotivated to participate in PE classes showed a positive attitude regarding practices with EXGs and demonstrated their willingness to collaborate with peers. The experiment also showed that exergaming provides situations in which students can increase the regularity of their practice of physical exercises.

School-based PE interventions are recommended to support an increase in moderate to vigorous physical exercise by modifying curricula to allow for more active time in PE class. Based on this context, Quinn (2013) investigated the inclusion of Just Dance and DDR into a traditional PE class to enhance the curriculum and increase student participation and activity time. Results indicated that during the post-intervention period, students were significantly more active in PE classes than prior to the intervention. Gao et al. (2013) investigated the impact of DDR-based exercise on 208 Latino school children (from the third and fifth grades). The DDR-based exercise intervention improved the children's cardiorespiratory endurance and math scores over time.

It has been advocated that the use of EXGs in schools may have many advantages. In health promotion, the use of EXGs against obesity has been studied by many researchers since these games provide a similar energetic demand as the recommendations from the American College of Sports Medicine for daily caloric expenditure (Biddiss \& Irwin 2010; Warburton 2009). According to Papastergiou (2009), the physically interactive games that have newly emerged can potentially enhance young people's physical fitness, motor skills, and motivation for physical exercise. In the pedagogical area, EXGs have attracted the educators' attention in schools and universities due to the large number of VGs that can be incorporated into the different disciplines of the PE curriculum (Staiano \& Calvert 2011). Thus, the power of the incorporation of EXGs in school curriculum relies basically on two aspects: the motivation generated by VGs and the usefulness of EXGs for physical activity in the contents of PE. 
Regarding the motivational aspect, Hansen and Sanders (2010) investigated kids' motivation to play an EXG, taking into account persistence in play. The authors investigated six elementary school students from a fifth-grade class. Results indicated that the persistence the players displayed was related to the flow theory, which is directly connected to their intrinsic motivation. This persistence of play was defined as a natural feature of children to engage voluntarily and remain engaged in technology-oriented physical activity. Epstein et al. (2007) studied the interactivity of 35 children between the ages of eight and twelve years old and found that DDR was more compelling than performing dance movements alone or while watching television. Similar results were found by Marijke et al. (2008), who investigated 27 primary school children who used Interactive Dance Video Game Simulation. In addition, it was found that multiplayer VGs also increase motivation among users.

The impact of EXGs in motivating elementary school children in PE classes was also studied by Sun (2012). Results indicated that students' situational interest in exergaming was significantly higher than in a group that did not interact with the technology. This evidence suggests that EXGs may have a strong motivational power, but it is premature to claim that they will increase physical activity enough for children to receive health benefits in PE. According to Maddison et al. (2009), EXGs can be used as intervention tools in PE by promoting an improvement in physical fitness in schools. Their use for weight loss has also been shown in the results presented by Mhurchu et al. (2008), as they found twelve-year-old children have lost measures of waist circumference playing DDR when compared to the children from a control group. According to Fiorentino and Gibbone (2005), the computer game Virtual Gym can increase children's physical activity levels while remaining sensitive to the many learning styles that typically appear in elementary school PE classes. They assert that the availability of virtual practice has the potential to improve motor skill competency and promote better understanding of movement principles. To advance levels or meet new opponents, users must demonstrate cognitive skills and manual dexterity in manipulating the joystick (Nintendo ${ }^{\circledR}$ Wii and PlayStation ${ }^{\circledR}$ Move), or they must show physical exertion and coordination in using their upper and lower limbs $\left(\mathrm{XBOX}{ }^{\circledR}\right.$ Kinect). It is important to highlight that several of these EXGs allow for the connection of different players simultaneously. Such a feature may be exploited to increase group participation in the same activity, decreasing exclusion and increasing cooperation or competitiveness. Therefore, these aspects could help the feasibility of using EXGs in the classes.

EXG consoles differ from sedentary VGs (Biddiss \& Irwin 2010) due to the physical exertion and physical capabilities required for the game. In fact, all games require cognitive activity, auditory and visual reaction time, and coordination of the fingers to manipulate the joystick. However, EXGs require other physical capabilities such as aerobic endurance, coordination, strength, balance, and flexibility to support the gameplay and the narrative of the games. Table 1 presents a summary of current commercial EXGs that may be used in PE classes. The game list is divided into contents of PE (games, gymnastics, fights, dance, and sports) and classified by the predominant physical capability developed by each game.

Table 1. Exergames consoles and five examples of games classified according to the contents of physical education (CEF) and the physical capabilities they require: motor coordination (general coordination, fine coordination, upper and lower limbs coordination), aerobic endurance, strength, balance and flexibility.

\begin{tabular}{|c|c|c|c|}
\hline & \multicolumn{3}{|c|}{ Consoles } \\
\hline & Nintendo $₫$ Wii & Xbox ${ }^{\circledR}$ Kinect & PS Move \\
\hline Sports & $\begin{array}{l}\text { Virtua Tennis } 4++ \\
\text { Wii Fit Plus }+++++ \\
\text { Tiger Woods: The Masters }+ \\
\text { Wii Resort Sports }+ \\
\text { Wii Sports }+\end{array}$ & $\begin{array}{l}\text { Virtua Tennis } 4++ \\
\text { Kinect Sports }++ \\
\text { Michael Phelps }{ }^{1}++ \\
\text { Tiger Woods: The Masters }+ \\
\text { London } 2012++\end{array}$ & $\begin{array}{l}\text { Virtua Tennis } 4++ \\
\text { Sports Champions } 2++ \\
\text { Racket Sports }++ \\
\text { MotionSports Adrenaline ++ } \\
\text { Brunswick Pro Bowling }+\end{array}$ \\
\hline Dance & $\begin{array}{l}\text { K-Pop Dance Festival ++ } \\
\text { Just Dance } 2015++ \\
\text { The Smurfs Dance Party ++ } \\
\text { Dance Dance Revolution ++ } \\
\text { The Black Eyed Peas }{ }^{3}++\end{array}$ & $\begin{array}{l}\text { Dance Central: Spotlight ++ } \\
\text { Just Dance } 2015++ \\
\text { Grease Dance }++ \\
\text { Zumba Fitness Rush ++ } \\
\text { Michael Jackson }{ }^{2}++\end{array}$ & $\begin{array}{l}\text { Get Up and Dance ++ } \\
\text { Just Dance } 2015++ \\
\text { Michael Jackson }{ }^{2}++ \\
\text { Dance on Broadway }++ \\
\text { Zumba Fitness ++ }\end{array}$ \\
\hline Games & Guitar Hero III Legends ${ }^{4}+$ & Twister Mania Kinect + & Kung Fu Rider + \\
\hline
\end{tabular}




\begin{tabular}{|c|c|c|c|}
\hline & $\begin{array}{l}\text { Wii Play }+ \\
\text { Crazy Mini Golf } 2+ \\
\text { Wii Play: Motion }+ \\
\text { Rock Band }++\end{array}$ & $\begin{array}{l}\text { Kinect Adventure }+ \\
\text { Wipeout } 2+ \\
\text { Harry Potter }+ \\
\text { Kinect Star Wars }+ \\
\end{array}$ & $\begin{array}{l}\text { Eye Pet }+ \\
\text { Start the Party! + } \\
\text { The Shoot }+ \\
\text { Datura }+\end{array}$ \\
\hline \multirow[t]{5}{*}{ Fights } & $\begin{array}{l}\text { Ready } 2 \text { Rumble Revolution } \\
++\end{array}$ & Kung Fu High Impact ++ & Sports Champions Sword ++ \\
\hline & All Star Karate ++ & Fighters Uncaged +++ & UFC Personal Trainer +++++ \\
\hline & Punch-Out!! ++ & Fighter Within +++ & The Fight: Lights Out ++ \\
\hline & Don King Boxing ++++ & Kinect Sports Boxing ++ & Sports Champions 2 Boxing ++ \\
\hline & Wii Sports Boxing ++ & UFC Personal Trainer +++++ & Kung Fu Live ++ \\
\hline \multirow[t]{5}{*}{ Gymnastics } & $\begin{array}{l}\text { Jillian Michaels Fitness } \\
+++++\end{array}$ & $\begin{array}{l}\text { Nike + Kinect Training } \\
+++++\end{array}$ & Move Fitness +++++ \\
\hline & The Biggest Looser +++++ & miCoach +++++ & Get Fit With Mel B +++++ \\
\hline & Gold's Gym +++++ & Your Shape Fitness ${ }^{6}+++++$ & EA Sports Active $2+++++$ \\
\hline & Wii Fit Plus +++++ & UFC Personal Trainer +++++ & UFC Personal Trainer +++++ \\
\hline & Your Shape Fitness ${ }^{6}+++++$ & EA Sports Active $2+++++$ & Fit in Six +++++ \\
\hline
\end{tabular}

Michael Phelps: Push the Limit ${ }^{1}$; Michael Jackson: The Experience ${ }^{2}$; The Black Eyed Peas Experience ${ }^{3}$; Guitar Hero III Legends of Rock ${ }^{4}$; Jillian Michaels Fitness Ultimatum 20105; Your Shape Fitness Evolved ${ }^{6}$.

Physical Capabilities + +++++ Motor coordination, aerobic endurance, balance, strength, flexibility ++++ Motor coordination, aerobic endurance, balance, strength +++ Motor coordination, aerobic endurance, strength ++ Motor coordination, aerobic endurance + Motor coordination

Source: Own study.

Therefore, if the proposed curriculum needs to specify a given physical capacity during the semester, teachers can choose from the different games the ones that deal with that particular physical ability. On the other hand, if the intention is to work with current PE themes such as sports, EXGs may also provide the necessary material to be used in classes. In addition, one of the advantages in using digital technologies in class is the ease of the visualization of the contents. For example, VGs such as NHL 2k11 (hockey), NBA 2k12 (basketball), FIFA SOCCER 12 (soccer), and NFL (American football) can be tools for studying technical aspects, pedagogical processes, rules, and tactics in the classroom.

Besides this, EXGs have good potential for composing an online PE curriculum. The use of the Internet within education has created an urgent need for research about online learning models, delivery methods, and curriculum content modifications, especially in online PE. In their research about online PE practices, Kooiman et al. (2015) discuss the need for more research in the area and the role PE professionals can take in defining how EXGs can be used online.

\section{Conclusions}

The school must consider the development of a new PE curriculum in which the key to promoting healthy physical activity in childhood is enjoyment. Nowadays, this aspect is fundamental in motivating students of different ages to move their bodies and have fun interacting with different activities in a way that was only previously experienced through traditional methods involving sports. Intrinsic motivation awakens the learning process at a high level of quality, therefore constituting a valuable goal to be sought in education. The use of EXGs in formal educational settings, according to the literature, has shown positive results in recent research, helping promote a healthier lifestyle and acting as an important component against the high rates of obesity among children and adolescents. EXGs have also attracted educators' attention in schools due to the variety of games that can be potentially incorporated as curricular activities. They can also incorporate technology into a curriculum that has historically been devoid of technological interventions.

\section{REFERENCES}

Ahn, M., Kwon, S., Park, B., Cho, K., Choe, S.P., Hwang, I., Jang, H., Park, J., Rhee, Y., \& Song, J. (2009). Running or gaming. In Proceedings of the International Conference on Advances in Computer Entertainment Technology, October 29-31, 2009 (pp. 345-348). Athens, Greece. DOI: 10.1145/1690388.1690455. 
Ballard, M., Gray, M., Reilly, J., \& Noggle, M. (2009). Correlates of video game screen time among males: Body mass, physical activity, and other media use. Eating Behaviors, 10, 161-167. DOI: 10.1016/j.eatbeh.2009.05.001.

Beck, J.C. \& Wade, M. (2004). Got Game? How the Gamer Generation Is Reshaping Business Forever. Cambridge, MA: Harvard Business School Press.

Benveniste, S., Jouvelot, P., Pin, B., \& Pequignot, R. (2012). The MINWii project: Renarcissization of patients suffering from Alzheimer's disease through video game-based music therapy. Entertainment Computing, 3, 111-120. DOI: 10.1016/j.entcom.2011.12.004.

Berkovsky, S., Bhandari, D., Kimani, S., Colineau, N., \& Paris, C. (2009). Design games to motivate physical activity. In Proceedings of the $4^{\text {th }}$ International Conference on Persuasive Technology, April 26-29, 2009 (pp. 26-29). Claremont, California, USA.

Biddiss, E. \& Irwin, J. (2010). Active video games to promote physical activity in children and youth. Archives of Pediatrics and Adolescent Medicine, 164, 664-672. DOI: 10.1001/archpediatrics.2010.104.

Boyle, E., Connolly, T.M., \& Hainey, T. (2011). The role of psychology in understanding the impact of computer games. Entertainment Computing, 2, 69-74. DOI: 10.1016/j.entcom.2010.12.002

Csikszentmihalyi, M. (1990). Flow: The Psychology of Optimal Experience. New York, NY: Harper Perennial.

Davis, F.D., Bagozzi, R.P., \& Warshaw, P.R. (1992). Extrinsic and intrinsic motivation to use computers in the workplace. Journal of Applied Social Psychology, 22, 1111-1132. DOI: 10.1111/j.1559-1816.1992.tb00945.x.

Easterly, D. \& Blachnitzky, A. (2011). Designing and evaluating UbiBall: A ubiquitous computing game for children. International Journal of Arts and Technology, 4(3), 276 - 293.

Elias, H., Mustafa, S.M.S., Roslan, S., \& Noah, S.M. (2010). Examining potential relationships between flow and motivational forces in Malaysian secondary school students. Procedia - Social and Behavioral Sciences, 9, $2042-2046$. DOI: $10.1016 /$ j.sbspro.2010.12.443.

Ennis, C.D. (2013). Implications of exergaming for the physical education curriculum in the $21^{\text {st }}$ century. Journal of Sport and Health Science, 2, 152-157. DOI: 10.1016/j.jshs.2013.02.004.

Entertainment Software Association (2014). Essential Facts about the Computer and Video Game Industry: Sales, Demographic and Usage Data. Retrieved June 26, 2014, from http://www.theesa.com/facts/pdfs/esa_ef_2014.pdf.

Epstein, L.H., Beecher, M.D., Graf, J.L., \& Roemmich, J.N. (2007). Choice of interactive dance and bicycle games in overweight and non-overweight youth. Annals of Behavioral Medicine, 33, 124-131. DOI: 10.1080/08836610701307835.

Ermi, L. \& Mäyrä, F. (2005). Fundamental components of the gameplay experience: Analyzing immersion. In Proceedings of the DiGRA Conference Changing Views: Worlds in Play, June 16-20, 2005 (pp. 1-14). Vancouver, Canada.

Finco, M.D., Reategui, E., Zaro, M.A., Sheehan, D., \& Katz, L. (2015). Exergaming as an alternative for students unmotivated to participate in regular physical education classes. International Journal of Game-Based Learning, 5, 1-10. DOI: 10.4018/IJGBL.2015070101.

Fiorentino, H. \& Gibbone, A. (2005). Using the virtual gym for practice and drills. Teaching Elementary Physical Education, 16, 14-16.

Fogel, V.A., Miltenberger, R.G., Graves, R., \& Koehler, S. (2010). The effects of exergaming on physical activity among inactive children in a physical education classroom. Journal of Applied Behavior Analysis, 43, 591-600. DOI: 10.1901/jaba.2010.43-591.

Gao, Z., Hannan, P., Xiang, P., Stodden, D.F., \& Valdez, V.E. (2013). Video game-based exercise, Latino children's physical health, and academic achievement. American Journal of Preventive Medicine, 44, 240-246. DOI: 10.1016/j.amepre.2012.11.023.

Gilmore, L.A., Duhé, A.F., Frost, E.A., \& Redman, L.M. (2014). The technology boom: A new era in obesity management. Journal of Diabetes Science and Technology, 8, 596-608. DOI: 10.1177/1932296814525189.

Graves, L., Stratton, G., Ridgers, N.D., \& Cable, N.T. (2007). Comparison of energy expenditure in adolescents when playing new generation and sedentary computer games: Cross sectional study. British Medical Journal, 335, $1282-1284$. DOI: $10.1136 / \mathrm{bmj} .39415 .632951 .80$.

Hansen, L. \& Sanders, S. (2010). Fifth grade students' experiences participating in active gaming in physical education: The persistence to game. ICHPER-SD Journal of Research, 5, 33-40.

Huizinga, J. (1949). Homo Ludens: A Study of the Play-Element in Culture. London: Routledge \& Kegan Paul.

Jackson, S.A. (1992). Athletes in flow: A qualitative investigation of flow states in elite figure skaters. Journal of Applied Sport Psychology, 4, 161-180. DOI: 10.1080/10413209208406459. 
Jackson, S.J., Eklund, B., \& Martin, A. (2010). The Flow Scales Manual. Queensland: Mind Garden.

Johnston, H. \& Whitehead, A. (2011). Pose presentation for a dance-based massively multiplayer online exergame. Entertainment Computing, 2, 89-96. DOI: 10.1016/j.entcom.2010.12.007.

Kiili, K. \& Perttula, P.T.A. (2012). Exerbraining for schools: Combining body and brain training. Procedia Computer Science, 15, 163-173. DOI: 10.1016/j.procs.2012.10.068.

Khoo, E.T., Merrit, T., \& Cheok, A.D. (2009). Design physical and social intergenerational family entertainment. Interacting with Computers, 21, 76-87. DOI: 10.1016/j.amepre.2012.11.023.

Kooiman, B.J., Sheehan, D.P., Wesolek, M., \& Retegui, E. (2015). Moving online physical education from oxymoron to efficacy. Sport, Education and Society, 20, 1-17. DOI: 10.1080/13573322.2015.1015978.

Kowert, R., Domahidi, E., Festl, R., \& Quandt, T. (2014). Social gaming, lonely life? The impact of digital game play on adolescents' social circles. Computers in Human Behavior, 36, 385-390. DOI: 10.1016/j.chb.2014.04.003.

Kwok, B.C., Clark, R.A., \& Pua, Y.H. (2015). Novel use of the Wii Balance Board to prospectively predict falls in community-dwelling older adults. Clinical Biomechanics, 30, 481-484. DOI: 10.1016/j.clinbiomech.2015.03.006.

Laikari, A. (2009). Exergaming - Gaming for health. In Proceedings of the $13^{\text {th }}$ IEEE International Symposium on Consumer Electronics, May 25-28, 2009 (pp. 665-668). Kyoto, Japan.

Lam, J.W.K., Sit, C.H.P., \& McManus, A.M. (2011). Play pattern of seated video game and active "exergame" alternatives. Journal of Exercise Science \& Fitness, 9, 24-30. DOI: 10.1016/S1728-869X(11)60003-8.

Lévy, P. (1997). Collective Intelligence: Mankind's Emerging World in Cyberspace. Cambridge, MA: Perseus Books.

Liao, L.F. (2006). A flow theory perspective on learner motivation and behavior in distance education. Distance Education, 27, 45-62. DOI: 10.1080/01587910600653215.

Lwin, M.O. \& Malik, S. (2014). Can exergames impart health messages? Game play, framing, and drivers of physical activity among children. Journal of Health Communication, 19, 136-151. DOI: 10.1080/10810730.2013.798372.

Maddison, R., Foley, L., Mhurchu, C.N., Jull, A., Jiang, Y., Prapavessis, H., Rodgers, A., Hoorn, S.V., Hohepa, M., \& Schaaf, D. (2009). Feasibility, design and conduct of a pragmatic randomized controlled trial to reduce overweight and obesity in children: The electronic games to aid motivation to exercise (eGAME) study. BMC Public Health, 146, 1-9. DOI: $10.1186 / 1471-2458-9-146$.

Marijke, J.M., Paw, M. J.M.C.A., Jacobs, E.P.G., Vaessen, W.M., Titze, S., \& Van Mechelen, M. (2008). The motivation of children to play an active video game. Journal of Science and Medicine in Sport, 11, 163-166. DOI: 10.1016/j.jsams.2007.06.001.

McGonigal, J. (2012). The Reality Is Broken: Why Games Make Us Better and How They Can Change the World. New York, NY: Penguin Press.

Mellecker, R.R. \& McManus, A.M. (2008). Energy expenditure and cardiovascular responses to seated and active gaming in children. Archives of Pediatrics and Adolescent Medicine, 162, 886-891. DOI: 10.1001/.162.9.886.

Mhurchu, C.N., Maddison, R., Jiang, Y., Jull, A., Prapavessis, H., \& Rodgers, A. (2008). Couch potatoes to jumping beans: A pilot study of the effect of active video games on physical activity in children. International Journal of Behavioral Nutrition and Physical Activity, 5, 1-5. DOI: 10.1186/1479-5868-5-8.

Mueller, F., Gibbs, M.R., \& Frank, V. (2010). Towards understanding how to design for social play in exertion games. Journal of Personal and Ubiquitous Computing, 14, 417-424. DOI: 10.1007/s00779-009-0268-x.

Osório, G., Moffat, D.C., \& Sykes, J. (2012). Exergaming, exercise, and gaming: Sharing motivations. Games for Health Journal, 1, 205-210. DOI: 10.1089/g4h.2011.0025.

Papastergiou, M. (2009). Exploring the potential of computer and video games for health and physical education: A literature review. Computers \& Education, 53, 603-622. DOI: 10.1016/j.compedu.2009.04.001.

Pijnappel, S. \& Mueller, F. (2013). 4 design themes for skateboarding. In Proceedings of the ACM SIGCHI Conference on Human Factors in Computing Systems, April 27-May 2, 2013 (pp. 1271-1274). Paris, France.

Prensky, M. (2003). Digital game-based learning. Computers in Entertainment, 1, 1-4. DOI: 10.1145/950566.950596.

Quinn, M. (2013). Introduction of active video gaming into the middle school curriculum as a school-based childhood obesity intervention. Journal of Pediatric Health Care, 27, 3-12. DOI: 10.1016/j.pedhc.2011.03.011.

Rosenberg, S. (2013). Cell phones and children: Follow the precautionary road. Pediatric Nursing Journal, 39, 65-70.

Rushkoff, D. (1996). Playing the Future: How Kids' Culture Can Teach Us to Thrive in an Age of Chaos. New York, NY: HarperCollins Publishers. 
Shernoff, D.J., Csikszentmihalyi, M., Schneider, B., \& Shernoff, E.S. (2003). Student engagement in high school classrooms from the perspective of flow theory. School Psychology Quarterly, 18, 158-176. DOI: 10.1521/scpq.18.2.158.21860.

Shin, N. (2006). Online learner's “flow” experience: An empirical study. British Journal of Educational Technology, 37, 705-720. DOI: 10.1111/j.1467-8535.2006.00641.x.

Sigmundová, D., El Ansari, W., Sigmund, E., \& Fromel, K. (2011). Secular trends: A ten-year comparison of the amount and type of physical activity and inactivity of random samples of adolescents in the Czech Republic. BMC Public Health, 11, 1-12. DOI: 10.1186/1471-2458-11-731.

Sinclair, J., Hingston, P., \& Masek, M. (2007). Considerations for the design of exergames. In The $5^{\text {th }}$ International Conference on Computer Graphics and Interactive Techniques in Australia and Southeast Asia, December 1-4, 2007 (pp. 289-295). Perth, Australia.

Singer, D.G. \& Singer, J. L. (2009). Imagination and Play in the Electronic Age. Boston, MA: Harvard University Press.

Singh, K., Granville, M., \& Dika, S. (2002). Mathematics and science achievement: Effects of motivation, interest, and academic engagement. The Journal of Educational Research, 95, 323-333. DOI: 10.1080/00220670209596607.

Sothern, M. (2004). Obesity prevention in children: Physical activity and nutrition. Nutrition, 20, 704-708. DOI: 10.1016/j.nut.2004.04.007.

Stach, T., Graham, T.C.N., Yim, J., \& Rhodes, R.E. (2009). Heart rate control of exercise video games. In Graphics Interface Conference, May 25-27, 2009 (pp. 125-132). Kelowna, Canada.

Suhonen, K., Väätäjä, H., Virtanen, T., \& Raisamo, R. (2008). Seriously fun: Exploring how to combine promoting health awareness and engaging gameplay. In MindTrek: Proceedings of the $12^{\text {th }}$ International Conference on Entertainment and Media in the Ubiquitous Era, October 7-9, 2008 (pp. 18-22). Tampere, Finland.

Staiano, A.E. \& Calvert, S.L. (2011). Exergames for physical education courses: Physical, social, and cognitive benefits. Child Development Perspectives, 5, 93-98. DOI: 10.1111/j.1750-8606.2011.00162.x.

Sun, H. (2012). Exergaming impact on physical activity and interest in elementary school children. Research Quarterly for Exercise and Sport, 83, 212-220. DOI: 10.1080/02701367.2012.10599852.

Sweetser, P. \& Wyeth, P. (2005). GameFlow: A model for valuating player enjoyment in games. Computers in Entertainment, 3, 1-24. DOI: 10.1145/1077246.1077253.

Thin, A.G., Hansen, L., \& McEachen, D. (2011). Flow experience and mood states while playing body movementcontrolled video games. Games and Culture, 6, 414-428.

Turkle, S. (1995). Life on the Screen: Identity in the Age of the Internet. New York, NY: Touchstone.

Vaghetti, C.A.O., Duarte, M.A., Ribeiro, P.O., \& Botelho, S.S.C. (2012). Using exergames as social networks: Testing the flow theory in the teaching of physical education. In Proceedings of SBgames 2012, XI Brazilian Symposium on Computer Games and Digital Entertainment, November 2-4, 2012 (pp. 29-37). Brasília, Brazil.

Voiskounsky, A.E., Mitina, O.V., \& Avetisova, A.A. (2004). Playing online games: Flow experience. PsychNology Journal, 2, 259-281.

Warburton, D.E.R., Sarkany, D., Johnson, M., Rhodes, R.E., \& Whitford, W. (2009). Metabolic requirements of interactive video game cycling. Medicine \& Science in Sports \& Exercise, 41, 920-926. DOI: 10.1249/MSS.0b013e31819012bd.

Zea, N.P, Sánchez, J.L.G., Gutiérrez, F.L., Cabrera, M.J., \& Paderewski, P. (2009) Design of educational multiplayer videogames: A vision from collaborative learning. Advances in Engineering Software, 40, 1251-1260. DOI: 10.1016/j.advengsoft.2009.01.023.

AUTHOR'S ADDRESS: Cézar Augusto Otero Vaghetti

Federal University of Pelotas

Superior School of Physical Education

625 Luiz de Camões Street

Pelotas/RS

E-mail: cesarvaghetti@gmail.com

Received: 19 March 2018; Accepted: 10 May 2018 